\title{
After the TEF and Consumer Law Based Interventions - Are Prospective HE Students Now Able to Make Informed Choices?
}

This article argues that recent government interventions in Higher Educationsome based in consumer law and others in the form of the Teaching Excellence Framework 'TEF' have failed to put prospective students in a position to make informed choices about courses or universities. Consumer law-based interventions do not give students all the information they need, although they may help to improve the standard of information and to control marketing excess. The TEF, with its focus on outputs rather than inputs similarly misses the mark. These failures are bad for students, and to the extent that Higher Education is a market which depends on students making informed choices, is bad for Higher Education.

Keywords: word; Teaching Excellence Framework; TEF; information, consumer law, higher education. 


\section{Introductory Remarks}

In this article, Higher Education (HE) sector policy initiatives, including the Consumer Rights Act 2015 (CRA) and Teaching Excellence Framework (TEF) will be considered in the light of the Government's stated aims of increasing competition and quality. ${ }^{1}$ Particular attention will be paid to the role of information in improving quality and competition. Limitations inherent in these initiatives will be suggested and consideration will be given as to whether they can be addressed by recent policy changes including TEF subject-level pilots. ${ }^{2}$ The article concludes that, while the policy changes may not have delivered an effective market, consumer regulation has encouraged HE providers to improve the integrity of information available to students on their chosen course.

\section{Context and Government Policy}

The HE sector has been subjected to regulatory reforms that seek to increase competition and introduce a market based ${ }^{3} \mathrm{HE}$ sector. Government policy sought to encourage the relationship between Higher Education Institutions (HEIs) and students to be one of business and consumer. ${ }^{4}$ Tuition fees have increased and the cap on student numbers has been removed, but questions continue to be raised about whether the market can effectively regulate HE to ensure that the $50 \%$ increase in funding since 2007/08 results in improved quality and value for money for students and tax payers. ${ }^{5}$

There is a paradox in Government policy. The stated intention is to deregulate on the supply side, moving towards what it describes as a "risk based approach", removing barriers to entry. ${ }^{6}$ The hands-off approach, promoting competition so as to achieve efficiencies, is not however applied consistently on the demand side. Instead, new forms of intervention, including legal regulation, have been introduced, not least in the form of the (TEF) and the (CRA). ${ }^{7}$

The justification given by Government policy for intervening in $\mathrm{HE}$ in the form of the CRA and TEF is to improve information available to students, as poor information could cause a market failure. ${ }^{8}$ Information in the HE context is seen as an

\footnotetext{
${ }^{1}$ Department for Business, Innovation and Skills, Success as a Knowledge Economy: Teaching Excellence, Social Mobility and Student Choice (Cm 9258, May 2016) 'The White Paper' Paper, 32.

${ }^{2}$ Department for Education, 'Teaching Excellence Framework: Subject level pilot specification' (DFE-182, 2017).

${ }^{3}$ Office of Fair Trading 'Higher Education in England, An OFT Call for information' (OFT 1529, March 2014) 'OFT CFI', 3.4.

${ }^{4}$ Provisions in the Higher Education and Research Act 2016 should make it easier for new providers to enter and failed providers to leave; Competition and Markets Authority 'UK higher education providers - advice on consumer protection law' (CMA 33, 12 March 2015) 11-12 'CMA Guidance'.

${ }^{5}$ Economic Affairs Committee, Treating Students Fairly: The Economics of Post-School Education ( HL 2017-19, 139); Committee of Public Accounts, The Higher Education Market, (HC 2017-19, 693).

${ }^{6}$ The White Paper (n 1) 19.

${ }^{7}$ Higher Education and Research Act 2017, s 25.

${ }^{8}$ Anthony Ogus, Regulation: Legal, Form and Economic Theory (Hart Publishing, 2004).
} 
essential element of Government policy to ensure certain desired outcomes. ${ }^{9}$ In terms of competition, access to information, which allows the consumer to differentiate between providers based on their preferences, was expected to drive effective competition in the HE market. ${ }^{10}$ It would encourage HEIs to be responsive to student preferences, to "raise their game, offering consumers a greater choice of more innovative and better quality products and services". ${ }^{11}$ Government policy linked the need for greater competition within the market with the availability of information and good graduate outcomes. Students, as informed consumers, are expected to make better informed choices which should enhance "student engagement, satisfaction, retention and success whilst at university and employability after university". ${ }^{12}$ While graduates are viewed, at one level, as critical to the UK economy and economic growth, ${ }^{13}$ for the graduates themselves, a university education warrants a strong graduate premium and low graduate unemployment rates. ${ }^{14}$ With students having invested heavily in their higher education, the ability to make an informed choice as to what and where to study is critical to the desired outcomes of high quality and student-focused higher education. $^{15}$

\section{Informed Choice for Students: The Challenges}

This section of the article will review the sources of available information, their shortcomings and official responses and reviews from the OFT Call for Information in 2014 to the 'Augar' report in 2019.

Prior to the introduction of the CRA and TEF, information available to prospective students included third-party 'choice tools ${ }^{\text {'16 }}$ such as websites and league tables. These private sources of information were supplemented by the government endorsed KIS data on the UniStats website, and information available on HEIs' websites. While the information provided through these channels has been regarded as increasingly 'user-friendly', ${ }^{17}$ issues have been identified concerning the quality of the information, and access to it. ${ }^{18}$ A Call for Information in 2014 by the OFT on HE in

\footnotetext{
${ }^{9}$ The Higher Education Market (n 5).

${ }^{10}$ OFT CFI (n 3) 4.5.

${ }^{11}$ White Paper (n 1) para 7; Competition and Markets Authority 'An effective regulatory framework for higher education: a policy paper'( CMA 42, 23 March 2015) 20, highlights that quality in the context of $\mathrm{HE}$ is difficult to define and can be interpreted differently by different students, institutions, employers and government, and students may also change their views about what quality means before, during or after their course. Any attempt to define quality by reference to a particular set of criteria carries the risk of excessive or uneven regulation. By contrast, the TEF makes an assumption of what the 'student' would define as quality.

${ }^{12}$ OFT CFI (n 3) para 4.4.

${ }^{13}$ The White Paper (n 1) para 9, refers to research that indicates a $1 \%$ increase in the share of the workforce with a university degree raises long-run productivity by between $0.2 \%$ and 0.5\%; and around 20\% of UK economic growth between 1982 and 2005 came as a direct result of increased graduate skills accumulation.

${ }^{14}$ White Paper (n 1) para 18, finding employment is identified as the most important outcome of higher education.

${ }^{15}$ CMA policy paper (n 11) para 1.5 .

${ }^{16}$ OFT CFI (n 3) para 4.9.

${ }^{17}$ OFT CFI (n 3) para 4.10.

${ }^{18}$ OFT CFI (n 3).
} 
England, dealing with the usefulness and accessibility of existing information, identified gaps in information about the learning experience and course outcomes. Accessibility of the information, and the way it was displayed gave cause for concern. ${ }^{19}$ The information required to provide a more 'rounded' picture of the learning environment included information on inputs such as contact hours, class size and teaching approach as well as employment prospects. ${ }^{20}$ As will be discussed later, TEF has not addressed these concerns.

The 2016 government White Paper which preceded the Higher Education and Research Act 2017 concluded that the conditions required to realise a freely competitive HE market did not exist. Poor information provision was identified as a key factor, with little market pressure on HEIs to present information to differentiate themselves, particularly on teaching quality. ${ }^{21}$ Students lack the information required to make an informed decision as to what and where to study ${ }^{22}$ which gives little incentive to HEI's to improve teaching quality. The White Paper seeks to provide "incentives for all institutions to improve and focus on what matters to students, to society and the economy". 23

Nobody would decry the desirability of the availability of valid information to help students make the best informed personal choice but $\mathrm{HE}$ is considered to be a "post-experience good", where the individual student may not be able to judge the personal benefit to them at the start of the course, and possibly not until some time after they have graduated. ${ }^{24}$ This limits the effectiveness of information available prior to selecting a course and provider for the individual student. The post-experience nature of education also limits the role that ex-ante information can play in promoting competition and an efficient market. As a post-experience good, the quality is not known before the student has been through university and quality can be interpreted differently by different students. ${ }^{25}$ Although increasing or mandating the availability of information can be seen as a low-cost non-intrusive regulation by law makers, its consequences can be to deter the adoption of better regulation, and to put burdens on enterprises while actually impairing consumers' decisions. Consumers can be overwhelmed by a surfeit of information and make economically rational decisions to ignore much of it. ${ }^{26}$ This places limits on how effectively the increase of information

\footnotetext{
${ }^{19}$ OFT CFI (n 3) para 4.12.

${ }^{20}$ OFT CFI (n 3) para 8.3.

${ }^{21}$ White Paper (n 1) para 19.

${ }^{22}$ White Paper (n 1) 43. The importance of these decisions is highlighted by the fact that they are 'one-off' decisions involving significant investment. High economic and social costs are associated with switching part way through a course and is thus unlikely, OFT CFI (n 3) para 4.2, and CMA Guidance (n 4) which highlights the importance of these decisions being properly informed and linked to consumer protection law.

${ }^{23}$ White Paper (n 1) 43.

${ }^{24}$ CMA policy paper (n 11) 17-18; Roger Brown, 'The Myth of Student Choice' [2012] 2 (2) VISTAS: Education, Economy and Community 7; David Weimer and Aidan Vining, Policy Analysis: Concepts and Practice (5 ${ }^{\text {th }}$ edn, Pearson 2016) 74.

${ }^{25}$ CMA Policy Paper (n 11) para 5.2.

${ }^{26}$ Onri Ben-Sharar and Carl E. Schneider 'The Failure of Mandated Disclosure' (2011) 159 University of Pennsylvania Law Review 647.
} 
and reliance on student choice can meet the wider objectives such as the enhancement of quality of teaching. ${ }^{27}$

The Review of Post-18 Education and Funding, led by Dr Philip Augar, concluded in 2019 that the removal of the control of student numbers, and a high fee cap aimed at creating a competitive market have failed to deliver competition on price, nor is competition on quality apparent. ${ }^{28}$ What competition there is appears to be for student numbers, with universities attempting to compete in the area of student experience, with increased spending on campus facilities, and also inducements such as lower entry requirements and unconditional offers. Of direct relevance to the question of the standard of information available to students is the sector's noticeable increase in its marketing effort, and the increased professionalism of that effort. The Augar report cautioned that Universities should maintain a sense of proportion in their marketing strategies and budgets.

\section{The First Response: Consumer Law-Based Interventions}

\subsection{Consumer Law and Government Policy}

The Competition and Markets Authority (CMA) considers that an effective system of consumer protection law can be an adequate source of market regulation to protect consumers provided they are "well informed about what they are purchasing, and not at risk of being significantly harmed by poor quality". ${ }^{29}$ Responses to the OFT $\mathrm{CFi}$ raised concerns that there were significant gaps in the information available to students as well as concerns about the accessibility of terms and conditions, the ability of students to understand them, and the extent to which they are fair and proportionate. ${ }^{30}$ The CMA published advice to help HEIs comply with consumer protection law and understand their responsibilities towards undergraduate students. ${ }^{31}$ The advice focuses on information provision terms and conditions and complaint handling and processes. ${ }^{32}$ The Augar report has highlighted the sector's increased marketing activities. Consumer protection law has an important role to play to ensure the accuracy of the marketing information.

\footnotetext{
${ }^{27}$ Roger Brown 'Competition and Choice in Higher Education' (2014) http://cdbu.org.uk/competition-and-choice-in-undergraduate-education \{accessed 8 August 2018\}; The OFT CFI (n 3) para 4.7; Graham Broadbent and Pamela Sellman 'Information, information, information ... overload?' (2014) 48 (3) The Law Teacher 359; Weimer and Vining (n 24), 74.

${ }^{28}$ Department for Education, Independent panel report to the Review of Post-18 Education and Funding (led by Dr Philip Augar, CP117, May 2019) 'the Augar report'

${ }^{29}$ CMA Policy Paper (n 11) para 7.1.

${ }^{30}$ OFT CFI (n 3) para 1.11; Concerns were also raised about the timeliness and accessibility of the processes that deal with student complaints and prompted the OFT to ask the CMA to undertake a compliance review to identify practices which may result in harm to students in breach of consumer protection legislation, para 1.13

${ }^{31}$ CMA Guidance (n 4)

${ }^{32}$ The CMA Guidance (n 4) focused on compliance with three pieces of consumer protection legislation: Consumer Protection from Unfair Trading Regulations 2008; Consumer Contracts (Information, Cancellation and Additional Charges) Regulations 2013 SI2013/3134; and unfair terms legislation
} 


\subsection{Consumer Law and Information}

With regard to information provision, the advice covers the information that must be provided to prospective students at three stages: research and application stage, offer stage and enrolment stage. ${ }^{33}$ For prospective students researching their choice of subject and institution, the focus of the consumer protection legislation is the imposition of a general duty not to make a misleading omission or, put more positively, for 'material information' to be provided in a way which is clear, intelligible, unambiguous and timely. ${ }^{34}$ 'Material Information' refers to the information which the average consumer needs, according to the context, to take an informed transactional decision. ${ }^{35}$ In this regard, the CMA highlights the importance to students of having full information about their courses and fees upfront. ${ }^{36}$

The intention of the CRA is to consolidate consumer law rights and obligations in one place. While the applicable information provisions discussed remain outside the scope of the Act, anything that is said or written pre-contract to the student in the provision of that information, e.g. in the prospectus, is treated as a term of the contract if taken into account by the student in deciding to enter into the contract. ${ }^{37}$ The CRA further consolidates the existing unfair terms legislation ${ }^{38}$ and all contracts, rules and regulations that students are bound by are subject to the test of fairness under the Act. ${ }^{39}$ The contract between the HEI and student is one for the provision of educational services under the Act and as such it provides that the service will be performed with reasonable care and skill. ${ }^{40}$ The CRA provides additional remedies, alongside the usual common law remedies, for breach of that duty and in the provision of inaccurate information with the introduction of a right to require repeat performance or a price reduction. ${ }^{41}$ The practicalities of having recourse to such remedies for poor teaching provision, and specifically repeat performance in the HE context, has however been questioned, as it can result in a loss of funding, career opportunities and living costs. ${ }^{42}$ Students rarely transfer provider and will not recover fees unless they can demonstrate

${ }^{33}$ CMA Guidance (n 4) 21.

${ }^{34}$ S 6(1) Consumer Protection from Unfair Trading Regulations 2008 (CPRs).

${ }^{35}$ Ibid. s.6(3)(a).

${ }^{36}$ CMA Guidance (n 4) 24 and 25 for a list of what 'course information' is taken to include, which of interest from a TEF perspective, includes 'information about the composition of the course and how it will be delivered, and the balance between the various elements, such as the number and type of contact hours that students can expect (for example, lectures, seminars, work placements, feedback on assignments), the expected workload of students (for example the expected self-study time), and details about the general level of experience or status of the staff involved in delivering the different elements of the course').

CMA Guidance (n 4) 30, highlights some potential overlap in 'material information under the CPRs and the 'pre-contract information' that must be provided under Consumer Contracts (Information, Cancellation and Additional Charges) Regulations 2013.

${ }^{37}$ CRA 2015, s 50.

${ }^{38}$ Unfair Terms in Consumer Contracts Regulations 1999 and Unfair Contract Terms Act 1977 consolidated in Part 2 of the CRA.

${ }^{39}$ CMA Guidance (n 4) 40; CRA 2015, s 62.

${ }^{40}$ CRA 2015, s 49, is a term of the contract that cannot be excluded, CMA Guidance, 65 , formerly provided in Supply of Goods and Services Act 1982, s 13.

${ }^{41}$ CRA 2015, ss 54 - 56; CMA Guidance (n 4), 66

${ }^{42}$ Salima Mawji 'Consumer Rights Act 2015: further and higher education' (June 2017) Westlaw Insight 
that they were misled. ${ }^{43}$ The value and deterrent effect on the HEIs of these remedies may well be limited. The lack of empowered consumers who can switch providers without financial penalty does not promote an effective market. ${ }^{44}$

\subsection{Consumer Law and Compliance}

Following publication of its advice, the CMA commenced a compliance review to establish whether the advice had been successful in raising awareness among HEIs of their consumer law obligations and whether compliance had improved. It further sought to identify whether evidence of non-compliance remained. ${ }^{45}$ While the review confirmed that awareness among HE providers had increased significantly with examples of positive change in practice, there were also examples of non-compliance, including with regard to the accessibility and adequacy of information provided to prospective students, for example in relation to additional course costs and undergraduate degree course variation. ${ }^{46}$ As such, consumer protection legislation to date has raised awareness of the need to provide accurate information but it is less clear whether it acts as an adequate source of market regulation to protect the interests of students as consumers and as an effective incentive to improve the quality of $\mathrm{HE}$ teaching provision. While the CRA introduces new remedies, the value of these remedies to consumers and their deterrent effect against breach by HEIs may be limited. Compliance with consumer protection provisions and specifically those set out in the CMA guidance continues to be a focus of regulation under the oversight of the Office for Students (OfS) which, as a consumer focused, sole market regulator, is also charged with administering the $\mathrm{TEF}^{47}$ and which has a role to play in responding to the recommendations in the Augar report. ${ }^{48}$

\section{The Second Response: the Teaching Excellence Framework}

\subsection{TEF and Government Policy}

The on-going work to improve HEIs' compliance with consumer protection legislation, the proliferation of available information in the form of KIS and league tables, and the post-experience nature of higher education which limits the impact information has on effective competition, has not diminished the Government's inclination to intervene. Improving information available to $\mathrm{HE}$ applicants is seen as essential for effective competition and the maintenance of quality. ${ }^{49}$ The CMA found that the HE sector in England is to a large extent characterised by healthy competition between providers which have a strong reputational incentive to provide high quality

\footnotetext{
${ }^{43}$ Public Accounts Committee (n 5), 12

${ }^{44}$ ibid

${ }^{45}$ Competition and Markets Authority, 'Consumer law compliance review, Higher Education undergraduate sector findings report' (CMA July 2016).

${ }^{46}$ Ibid, 4, 17 - 18.

${ }^{47}$ White Paper (n 6) 66. Higher Education and Research Act 2017, ss 23-25; Office for Students 'Securing student success: Regulatory framework for higher education in England. (OfS 2018.01, February 2018). To simplify the HE regulatory environment, the OfS combines the regulatory functions of HEFCE and OFFA. Compliance with the CMA advice is a condition of registration of a provider with the OfS.

${ }^{48}$ The Augar report (n 28).

${ }^{49}$ The Higher Education Market (n 5).
} 
education and to actively compete for students, but still concluded that students find it difficult to assess the quality of courses before they start. A wrong choice can result in a poor learning experience and long term detriment to career outcomes, which justifies the need for further regulation. ${ }^{50}$ The White Paper maintained that good quality teaching results in good graduate outcomes and as such teaching quality should be among the 'key drivers' of a prospective student's choice and their investment in HE. ${ }^{51}$ The information available to students however "can be hard to find, inconsistent and inadequate, making it hard to form a coherent picture of where excellence can be found within and between different higher education providers". ${ }^{52}$ Further, the White Paper advances the view that the type of information available (and required under consumer protection legislation) fails to match students' needs and priorities. ${ }^{53}$

The TEF seeks to address these shortcomings with existing information provision by introducing "sector-wide rigour to the assessment of teaching excellence." "54 The Government's position is that TEF provides "clear, understandable information" to students, supported by a rating system which indicates where teaching quality is outstanding, with the aim of making it clear to students where the best provision can be found. It should inform competition within the HE market and drive up the standards of quality as a result. ${ }^{55}$

\subsection{Teaching Excellence Framework shortcomings}

The purpose behind the TEF is laudable and all-encompassing: to better inform students about what and where to study, to raise esteem for teaching, to recognise and reward excellent teaching and better meet the needs of employers, business, industry and the professions in identifying the best graduates. ${ }^{56}$ The priorities, in assessing quality and in choosing what and where to study, were identified as contact hours, class size and lecturer training, for which a lack of information is said to exist. ${ }^{57}$ These input metrics did not appear in the second version of TEF 'TEF2' but were intended to appear in some guise in the TEF subject level pilot study. TEF takes quantitative data from the National Student Survey NSS, ${ }^{58}$ HESA $^{59}$ and ILR ${ }^{60}$ and the Destination of Leavers Survey from Higher Education (DLHE). ${ }^{61}$ These metrics have been criticised as unreliable 'proxy' measures of quality in learning and teaching in HE. ${ }^{62}$ In addition, a

\footnotetext{
${ }^{50} \mathrm{CMA}$ policy paper (n 11) $17-18$.

${ }^{51}$ White Paper (n 1) 43.

${ }^{52}$ Ibid, 43-44.

${ }^{53}$ Ibid, 44

${ }^{54}$ Ibid, 44

${ }^{55}$ Ibid, 13.

${ }^{56}$ Department for Education 'Teaching Excellence Framework and Student Outcomes Framework Specification' (DFE 272, 2017), 'TEF Year Two', 7.

${ }^{57}$ White Paper (n 1) 44.

${ }^{58}$ The National Student Survey will be used to measure teaching quality with reference to the teaching on my course (NSS Q1-4), assessment and feedback (NSS Q5-9) and the learning environment with reference to academic support (NSS Q10-12).

${ }^{59}$ Higher Education Statistics Agency

${ }^{60}$ Individualised Learner Record data collected by the HEI which is used to measure noncontinuation.

${ }^{61}$ Will be used to measure student outcomes and learning gain with reference to employment or further student and highly skilled employment or further study, 6 months after graduation.

62 Mike Neary, 'Teaching Excellence Framework: a critical response and an alternative future' (2016) 12 (3) Journal of Contemporary European Research 690, 691; Royal Statistical
} 
15-page written statement by the providers ${ }^{63}$ defined the metrics by which teaching excellence should be judged by the criteria of: teaching quality, learning environment and student outcomes and learning gain. ${ }^{64}$

It was said that the link between TEF and increase in student fees was worth $£ 1$ billion $^{65}$ which was seen as an incentive to HEI to focus on education, but this figure should be viewed in the context of the existing $£ 28$ billion University income, the majority of which comes from education. ${ }^{66}$ If education income has not driven market forces to improve the quality of education provision before TEF, it is by no means certain that it will do so subsequently. The conversion of existing information into a simplified eye-catching label is more likely to feed into the reputational differentiation of universities. The results of TEF2 have not disturbed the Oxbridge and Russell Group reputational position. ${ }^{67}$

\subsection{All outputs, no inputs}

TEF uses existing data as proxies for teaching quality. The extent to which these give a valid picture of quality has been subject to criticism elsewhere. ${ }^{68}$ The concern addressed here is that, while other pre-existing data sets did not ignore inputs such as staff student ratios (SSR), ${ }^{69}$ to date TEF is based entirely on outputs. The TEF benchmarking process ${ }^{70}$ does not take account of the impact of factors such as tariff entry points and cross-subsidising of courses and other input data. This is surprising considering that the Government acknowledges that what "best predicts educational gain is measures of educational process: what institutions do with their resources to make the most of whatever students they have." 71 The various Government reports discussed in this paper acknowledge the role of inputs such as contact hours but there is evidence that Russell Group and Gold-rated institutions tend to have the largest class

Society : Response to the Teaching Excellence and Student Outcomes Framework (TEF Subject-Level Consultation, 21 May 2018).

${ }^{63}$ In $22 \%$ of judgements the panel used their discretion to revise the metrics outcome following consideration of the written statements. For HE or alternative providers the move was mainly from bronze to silver although three were downgraded, silver to bronze. More Further Education colleges were downgraded.

${ }^{64}$ TEF Tear 2 (n 56) 23.

${ }^{65}$ White Paper (n 1) 51

${ }^{66}$ Universities UK, 'University Spending Explained' $<$ http://www.universitiesuk.ac.uk/factsand-stats/Documents/university-spending-explained-summary.pdf $>$ accessed 8 August 2018\}

${ }^{67}$ OfS 'TEF outcomes' $<$ https://www.officeforstudents.org.uk/advice-andguidance/teaching/tef-outcomes/\#/> accessed 8 August 2018. Oxbridge is a colloquial expression for the universities of Oxford and Cambridge while the Russell group are 24 of the UK's leading universities https://russellgroup.ac.uk/

${ }^{68}$ Neary (n 62)

${ }^{69}$ Most league tables take account of staff student ratios and entry tariffs points. The Guardian League table gives a value added score and spend per student.

70 The TEF benchmarking process takes account of characteristics of the students at the provider, including factors such as age, ethnicity and subject of study. Each provider has a unique benchmark based on its students' characteristics.

${ }^{71}$ Graham Gibbs Dimensions of quality (Higher Education Authority, 2010), 43; Department for Education 'Teaching Excellence Framework: Subject level pilot specification' (DFE 182, July 2017), 44. 
sizes. ${ }^{72}$ When surveyed as part of the TEF implementation process, students considered class size as one of the least important factors for determining quality. ${ }^{73}$ There is however evidence that students may learn more in smaller groups ${ }^{74}$ and that contact hours and large class sizes are considered to have impacts on students' perception, engagement and depth of learning. ${ }^{75}$ Rather than relying on a survey of applicants and students, further research appears to be needed to support decisions about optimum class size and contact hours in HE.

The pilot on teaching intensity, as part of the subject level pilot, sought to redress the balance between outputs and inputs. ${ }^{76}$ The teaching intensity pilot looked at class sizes and SSR per class through two metrics: hours and group size, although it did not differentiate between teaching by lectures or seminars or grade and experience of staff. A weighting based on number of hours taught by the SSR for each hour gave a Gross Teaching Quotient. ${ }^{77}$ To increase validity, data was taken not only from providers but also took into account students' perception of whether the contact hours were sufficient for their studies. This data was intended to be supplementary to the subject-level metrics and considered as part of the holistic judgement in the second step alongside other narrative background information submitted by providers. It was hoped the pilot would inform the extent to which the assessors could use the teaching intensity data to make judgements and how to expand the collection of the data in the future. ${ }^{78}$ It may also contribute evidence on the relationship between teaching intensity and teaching excellence. ${ }^{79}$ Following the subject level consultation in 2018, measuring teaching intensity was removed from TEF. ${ }^{80}$ Neither the respondents to the consultation, mainly HEIs, or the TEF panel members thought the measure meaningful. The Government also referred to the research commissioned as part of the TEF review, to claim that teaching intensity was of low relative importance in student decision making. ${ }^{81}$ As discussed earlier the validity of this research in determining the quality of education requires further research and evaluation.

While teaching intensity was dropped, metrics on Longitudinal Education Outcomes (LEO) data looking at employment and earnings outcomes up to 5 years after graduation will be included as a core metric, in addition to the existing graduate salary metric from the DLHE survey. ${ }^{82}$ This is said to 'strengthen the way that TEF holds providers to account for delivering excellent teaching'. However, rather than trying to

${ }^{72}$ Jonathan Reeves and Nick Hillman The 2019 Student Academic Experience Survey (HEA, 2019), 35.

${ }^{73} \mathrm{D}$ Vivian and others, TEF and informing student choice (IFF Research, DFE-RR824, June 2018) 60.

${ }^{74}$ Reeves (n 72).

${ }^{75}$ Gibbs (n 71); White Paper (n 1).

${ }^{76}$ TEF Subject level pilot specification (n 71) the same set of 10 TEF criteria used for TEF Year 2 are used for 35 subjects identified by HESA.

${ }^{77}$ TEF Subject level pilot specification (n 71), 63.

${ }^{78}$ Department for Education 'Teaching Excellence and Student Outcomes Framework: subject level Consultation Document (DFE 12 March 2018), 28.

${ }^{79}$ Ibid and TEF Subject level pilot specification (n 71), 49, the pilot will consider whether bands are the best way to express the data and where they should fall.

${ }^{80}$ Department for Education, Teaching Excellence and Student Outcomes Framework: subject level, Government consultation response (DFE 310-2018) 11.

${ }^{81}$ Vivian (n 73) $56-57$.

${ }^{82}$ Department for Education 'Teaching Excellence and Student Outcomes Framework: lessons Learned from Year Two (DFE 271, October 2017), 47 
assess the quality of activity in the classroom, greater emphasis is being placed on economic factors such as graduate earnings. TEF is moving towards a rating based on economic data supplemented by the provider's narrative. LEO measures concrete data but its value may be lost when combined with other proxies to give the simplistic TEF rating. If the objective is to improve information available to students, then the wider publicity and availability of LEO will allow students to consider the information themselves.

The result of the Government consultation is that TEF, at both provider and subject levels, relies entirely on outputs. Omitting inputs such as tariff entry points, SSR, contact hours and class size will influence the actions HEIs will take to improve their TEF rating. Research indicates that there is a perception that TEF may have contributed to increased activity on employability, student support, and initiatives to improve teaching standards and qualifications but also a decrease in teaching morale particularly for Bronze award providers. ${ }^{83}$ It looks as though TEF will remain. The Secretary of State for Education when outlining his priorities in September $2019^{84}$, urged the Office for Students to publish a subject level TEF in 2021 and implement a new TEF model, following the government response to the independent review of the TEF led by Dame Shirley Pearce, publication of which was awaited at the time of writing.

\subsection{Government policy has lost important policy levers}

TEF was intended to inform students on teaching quality but the metrics are increasingly focused on economic outputs after graduation. By contrast students have little information from TEF or HEIs on how the money they borrow to fund their education is spent. Government policy to deregulate the sector and introduce student loans, in a failed attempt to reduce the budget deficit, ${ }^{85}$ has lost the Government an important policy lever. The relative per student income to the HEI for providing different courses has changed. The higher cost 'Group A' courses such as medicine saw income increase by only 6\% between 2011 and 2017. For 'Group D', low-cost humanities courses, funding increased by $47 \%$. The Augar report observed that increasing student loans and reducing grant funding resulted in the funding of some subjects increasing at twice the rate of others and that this difference bore relationship with the cost of provision. ${ }^{86}$ The Augar report recognised this as an unintended consequence of HE funding policy which has resulted in the apparent over funding of low cost subjects and the underfunding of high cost subjects. Universities UK's submission to the Augar report recognised that the $£ 9000$ fee is well in excess of the $£ 7500$ average cost of providing undergraduate courses but falls far short cost of more

${ }^{83}$ David Vivian and others Evaluation of Provider-level TEF 2016-17 (Year 2) (DFE-RR881, January 2019) 94, 15\% of applicants made use of TEF to help them in their decision making although this increased to $34 \%$ of applicants who were aware of TEF at the time of their application.

${ }^{84}$ Letter from Secretary of State for Education to the Chair of the Office for Students (16 September 2019).

${ }^{85}$ Chris Belfield and others, 'Higher Education funding in England: past, present and options for the future' (Institute for Fiscal Studies Briefing Note BN211, July 2017) IFS Briefing Note

BN211'. Since 2011, the contribution of HE spending to the deficit has declined by $£ 5.7$ billion (around 10\% of the current deficit), while university funding has increased.

${ }^{86}$ The Augar Report (n 28) 72. 
expensive subjects such as $£ 22,000$ for veterinary science. This could influence Universities' incentives to move from the more expensive STEM subjects to 'chalk and talk' subjects such as Law. There has already been a higher increase in students studying social sciences and business administration than STEM subjects with the Government spending 30 per cent more per student on creative arts degrees than engineering degrees. ${ }^{87}$ The Government's ability to influence and encourage more students to enter STEM subjects is reduced, which is at odds with its Industrial Strategy.

\subsection{Increase in resources should be matched by increase in disclosure}

University income from fees has increased by $25 \%$ since the 2012 funding reforms. ${ }^{88}$ This increase has outstripped wider public spending and GDP growth and impacts the Government deficit by over $£ 10$ billion. ${ }^{89}$ The increased income and move to a market based approach to HE has not been accompanied by any significant review of governance of HEIs, nor any increase in financial disclosure requirements. While TEF has increased the focus on projected student earnings, an economic output, there is no consideration of differing financial inputs. When income for HE was entirely state provided and more modest, oversight by Government bodies such as HEFCE might have been adequate. The significant real terms rise in HE funding, in comparison with other sectors and international comparators requires more public scrutiny. The Augar report questioned UK Universities' size of surplus at $£ 1000$ per student while proportionally less was spent on direct teaching than counterparts overseas. There is also evidence of a wide disparity of spend on similar subjects at apparently similar institutions.

Government policy has encouraged the risk of maintaining quality to remain almost entirely with students and taxpayers rather than being transferred to the institutions. In an era of increasing income from fees, governance of HE providers and the information on how they spend their students and tax payers' money appears to be inadequate.

Higher education is one of the largest financial commitments any young person can make, the cost of which they have to repay over their working life. Only $20 \%$ of students consider they are given enough information on how their fees are spent. ${ }^{90}$ While a few HE providers do volunteer information on financial spending in a user friendly form, the practice is not as ubiquitous as it is for local authorities or even privatised utilities. It should become obligatory for HE providers to disclose how their spending is split between research, education, estates, administration and how much is spent per student on particular courses of study. The move to subject level TEF is an opportunity for HE providers to disclose spending per student by course.

Students studying the low-cost 'Group D' courses could consider not only their earning potential but also whether their fees are cross subsidising other students. Full transparency would also ensure that increased funding benefits the student and their education. ${ }^{91}$ Some of the financial data might be complex but it could be re-packaged

${ }^{87}$ The Augar Report (n 28) 81.

${ }^{88}$ Belfield (n 85).

${ }^{89}$ The Augar Report (n 28) 92.

${ }^{90}$ Reeve (n 72) 14.

${ }^{91}$ While over $50 \%$ of students considered spending on campus development was a reasonable use of tuition fees, spending less on buildings and sports/social facilities was seen as the most preferred way to save money. Jonathan Neves and Nick Hillman, 'The 2017 Student Academic Experience Survey' (HEA, 2017), 48. 
by third party intermediaries, including the private league tables, to be user friendly for potential students. Disclosure and transparency would also allow for better independent scrutiny of individual HE providers financial and management performance.

\section{Conclusion}

Recent changes to consumer regulation, including the CRA, have delivered an ethos in which HEIs take greater care in the information provided to applicants and students. This is important to check any excesses of marketing when other policy changes have resulted in an increase in funding but have not delivered an effective market for price or the quality of education. TEF was intended to focus HEIs on teaching quality. It appears to be too early to say if this has made a significant impact on teaching quality or student decision making. Forthcoming changes such as subject level TEF appear unlikely to include teaching quality inputs rather than economic outputs, but the independent review of the TEF led by Dame Shirley Pearce may address this. This and government implementation of recommendations in the Augar report are an opportunity to address a number of shortcomings, but the existence of a market in higher education has been called into question, and the policy of relying on information to regulate quality has significant limitations. As the increase in spending on higher education has outstripped other sectors and now gives a significant surplus, there should be a corresponding increase in disclosure and transparency. Students should have access to more information on how their fees are spent, including, crucially, the costs of providing their chosen course. 